\title{
ANÁLISE DE IMAGEM EM QUÍMICA ANALÍTICA: EMPREGANDO METODOLOGIAS SIMPLES E DIDÁTICAS PARA ENTENDER E PREVENIR O ESCURECIMENTO DE TECIDOS VEGETAIS
}

\author{
Karina Omuro Lupetti, Lucinéia Cristina de Carvalho, André Farias de Moura e Orlando Fatibello-Filho* \\ Departamento de Química, Universidade Federal de São Carlos, CP 676, 13560-970 São Carlos - SP
}

Recebido em 5/1/04; aceito em 6/8/04; publicado na web em 14/1/05

\begin{abstract}
IMAGE ANALYSIS IN ANALYTICAL CHEMISTRY: DIDACTIC AND SIMPLE METHODOLOGIES TO UNDERSTAND AND PREVENT THE BROWNING OF VEGETABLE TISSUES. A simple and didactic experiment was developed for image monitoring of the browning of fruit tissues caused by the enzyme polyphenol oxidase. The procedure, easy and inexpensive, is a valuable tool to teach and demonstrate the redox reaction between the enzyme and the natural polyphenols. To obtain the browning percentage for apple, pear and banana, digital photographs were employed, and the images were analyzed by means of Monte Carlo methods and digital analysis programs. The effects of several experimental conditions were studied, such as pH, light, temperature and the presence of oxygen or anti-oxidants. It was observed that each fruit presented a different condition that better minimized the oxidation process. The absence of oxygen and the application of a bissulphite solution were sufficient to keep the quality of all fruits tested.
\end{abstract}

Keywords: enzymatic browning; Monte Carlo methodology; digital image analysis.

\section{INTRODUÇÃO}

A Lei de Diretrizes e Bases da Educação Nacional (Lei 9394/96) mostra uma tendência de mudança no modelo de curso superior, privilegiando o papel e a importância do estudante no processo de aprendizagem, em que o papel do professor de "ensinar conceitos e soluções", passe a ser "ensinar o estudante a aprender conceitos e soluções". Nessas novas normas aplicáveis também às ciências Químicas, há necessidade de compreender seus conceitos, leis e princípios; conhecer as propriedades físicas e químicas principais dos elementos e compostos, que possibilitem entender e prever seu comportamento físico-químico, aspectos da reatividade, mecanismos e estabilidade; acompanhar e compreender os avanços científicotecnológicos e educacionais e reconhecer a Química compreendendo os aspectos históricos de sua produção e suas relações com os contextos cultural, sócio-econômico e político ${ }^{1,2}$.

Desenvolvendo-se e aplicando-se metodologias de ensino variadas, utilizando-se laboratórios ou mesmo a sala de aula com experimentos demonstrativos relacionados à Química do cotidiano, contribui-se para o desenvolvimento intelectual dos estudantes e despertase o interesse científico em adolescentes que poderão vir a ser futuros pesquisadores.

No ensino do conceito de mecanismos de reações de oxidaçãoredução, muitas vezes não se tem a preocupação em associar os conteúdos das disciplinas do ensino em geral com fenômenos que podemos observar no cotidiano, muitas vezes esclarecedores, como o escurecimento de frutos e vegetais e a sua maior preservação na presença de algumas substâncias ou de determinadas condições de armazenagem.

Por outro lado, a indústria de alimentos apresenta como uma das principais preocupações, a preservação dos produtos que comercializa, buscando metodologias para manter o sabor, a aparência, o valor nutritivo e prevenir a formação de compostos tóxicos em alimentos in natura ou que serão processados. A complexidade do processamento de alimentos associada à necessidade de aumentar $\mathrm{O}$

*e-mail: bello@dq.ufscar.br período de armazenamento torna o produto vulnerável à deterioração oxidativa. Portanto, é necessária a utilização de substâncias químicas capazes de oferecer proteção contra oxidação.

$\mathrm{O}$ escurecimento de frutas e de certos vegetais é iniciado pela oxidação enzimática de compostos fenólicos pelas polifenóis oxidases (PPO). O produto final da oxidação é a quinona, que ou se polimeriza, formando um pigmento escuro insolúvel, denominado melanina, ou reage não enzimaticamente com outros compostos fenólicos, aminoácidos e proteínas, formando também melaninas.

A prevenção da oxidação em tecidos vegetais pode se dar através de procedimentos físicos ou químicos. Os processos físicos de conservação dos alimentos, como desidratação, armazenamento a baixas temperaturas e tratamentos térmicos, apesar de serem os mais adotados, possuem uma série de limitações. Alguns alimentos não podem passar por estes processos, pois podem alterar suas propriedades organolépticas, como sabor e odor. Outras possibilidades consistem em retirar o oxigênio do meio e controlar a luminosidade utilizando embalagens adequadas, a vácuo e não-transparentes e/ou utilização de conservantes (antioxidantes). Alguns conservantes podem ser utilizados como o bissulfito de sódio (hidrogenossulfito de sódio), ácido ascórbico, ácido cítrico, butil-hidroxianisol (BHA), butil-hidroxitolueno (BHT), tocoferóis e EDTA, entre outros. Para cada substância adicionada, deve-se sempre respeitar as doses máximas permitidas, considerando a ingestão diária tolerada de cada composto $^{3}$.

\section{Análise de imagem}

Uma das principais formas de se avaliar o grau de deterioração de alimentos é através de técnicas de análise de imagens, que visam quantificar alterações de coloração ao longo do tempo. Existem na literatura ${ }^{4-6}$ diversos procedimentos para análise de imagens, que são obtidas com uma câmera digital e analisadas em um microcomputador por programas que computam todos os elementos gráficos das imagens ("pixels"), permitindo diferenciar padrões (e.g., claro-escuro, tons de cinza ou alguma coloração específica) e obter relações numéricas entre estes padrões. 
Wang e Sun ${ }^{4}$ desenvolveram um método não acoplado em computador para análise das propriedades do queijo cheddar, que durante seu cozimento apresenta escurecimento. Para o cálculo do fator de escurecimento (BF, "browning factor"), utilizou-se a relação de tons de cinza $(\mathrm{GV})$ antes e depois do cozimento (Equação 1)

$$
B F=\frac{G V_{0}}{G V_{t}}
$$

onde $\mathrm{GV}_{\mathrm{t}}$ é o valor total de cor cinza presente nas fatias de queijo cozidas por um determinado tempo te $\mathrm{GV}_{0}$, o valor inicial de tons de cinza nas fatias de queijo. Os resultados indicaram que o método é objetivo e que o fator de escurecimento é um parâmetro adequado para se avaliar a deterioração do queijo durante o processamento.

Steinmetz et al..$^{5}$ desenvolveram um procedimento utilizando uma câmera fotográfica e um espectrofotômetro para previsão da quantidade de açúcar contido em maçãs. A análise de imagens pode fornecer informação sobre a coloração da fruta, que pode ser relacionada com a quantidade de açúcar no fruto.

Um novo projeto de análise de imagens para uma detecção mais precisa de manchas de frutas foi pesquisado por Yang e Marchant ${ }^{6}$. A detecção consiste em duas etapas: segmentação inicial e refinamento. Na primeira, as manchas são segmentadas grosseiramente e na segunda, uma integração algorítmica é aplicada para refinar a segmentação, para obter uma melhor localização e um tamanho mais preciso da mancha detectada. Os testes iniciais para amostras de imagens de maçãs mostraram resultados promissores.

\section{Método de Monte Carlo}

A determinação de áreas em análises de imagens pode ser feita por metodologias de Monte Carlo, que têm a vantagem de não necessitar de recursos computacionais sofisticados, podendo ser aplicadas mesmo sem o uso de qualquer computador.

O método de Monte Carlo tem sido largamente empregado em diversas áreas da Física, tendo obtido grande sucesso em aplicações de Física Térmica e de Reatores ${ }^{7}$. A idéia central deste tipo de metodologia é a utilização de funções de distribuição de probabilidade $(f d p)$ para se resolver problemas que não sejam tratáveis de forma analítica como, por exemplo, a solução numérica de integrais multidimensionais ${ }^{8}$. Na prática, utiliza-se uma seqüência de eventos aleatórios cujo resultado deve obedecer a uma distribuição de probabilidade conhecida. Um exemplo clássico deste tipo de aplicação foi o experimento realizado pelo Conde de Buffon em 1733, em que o valor de $\pi$ foi calculado a partir de uma seqüência de lançamentos de agulhas sobre uma superfície contendo diversas linhas paralelas. Este experimento pode ser repetido atualmente por meio de programas computacionais que simulam o lançamento aleatório de agulhas ${ }^{9,10}$.

Observando estas interessantes propriedades que envolvem a preservação de alimentos e a possibilidade de desenvolver uma metodologia voltada para o Ensino de Química, realizou-se uma série de experimentos onde o escurecimento de diversas frutas foi quantificado através da análise de imagens obtidas em diferentes condições experimentais, comparando-se os resultados obtidos com a metodologia de Monte Carlo e os obtidos com metodologias padrão e avaliando-se os efeitos das diversas condições empregadas sobre o escurecimento dos tecidos.

\section{PARTE EXPERIMENTAL}

\section{Material e equipamentos}

Foram selecionadas frutas normalmente encontradas em merca- dos da região de São Carlos para os estudos de prevenção à oxidação, dentre elas maçã Gala (Malus sp), pêra Williams (Pyrus communis) e banana nanica (Musa ssp). Para obtenção das fotos dos diferentes tecidos utilizou-se uma câmera digital Kodak DC 50, com zoom Digital Science, que foram visualizadas em um computador K-6 com auxílio do programa Photo Enhancer (Figura 1). As fotos foram obtidas sempre nas mesmas condições de luminosidade, com o auxílio de uma lâmpada branca presa a um suporte universal e fundo azul para melhor visualização do padrão de escurecimento. Foi utilizado como método comparativo de análise de imagem o programa GIMP, disponível via internet ${ }^{11}$.

As diferentes frutas foram lavadas primeiramente com água corrente e depois com água desionizada, secas com papel toalha, cortadas com o auxílio de uma faca e acondicionadas em placas de Petri de 10 e $15 \mathrm{~cm}$ de diâmetro. Soluções antioxidantes foram adicionadas sobre cada fatia do tecido com o auxílio de uma micropipeta de 50-200 $\mu \mathrm{L}$ (Jencons-Sealpatte), mantendo-se as placas de Petri tampadas durante os ensaios de oxidação.
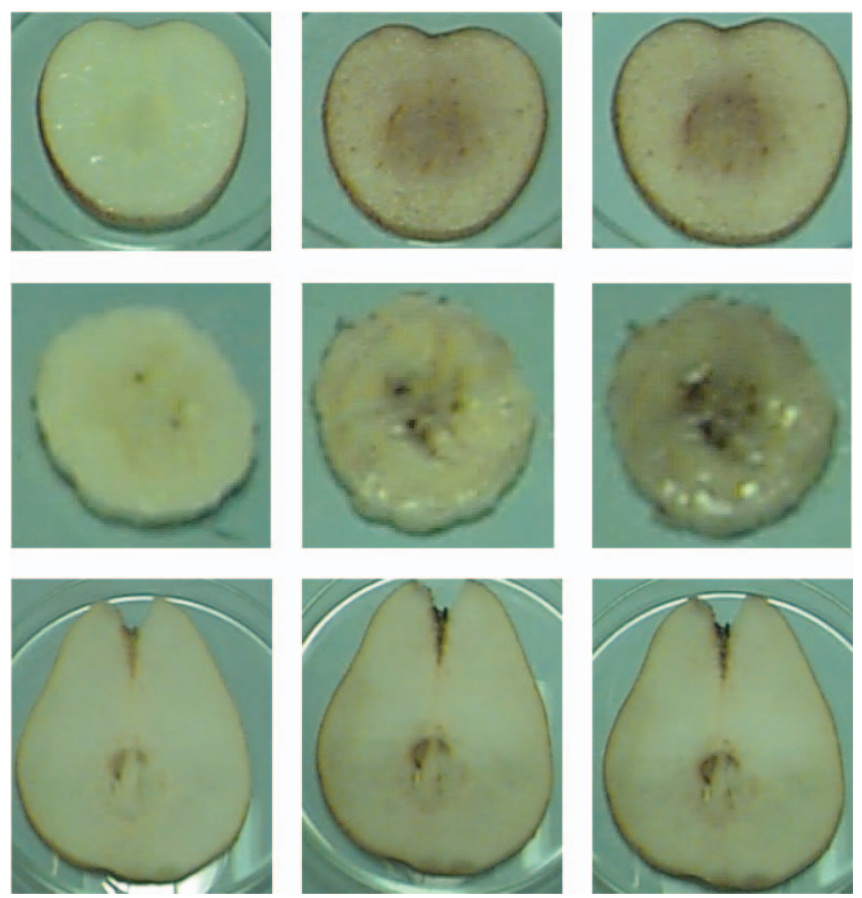

Figura 1. Seqüência de fotos tiradas com câmera digital para o acompanhamento do escurecimento dos tecidos de maçã, banana e pêra em diferentes condições: maçã, em tempos de 0,2 e 4 h a $50{ }^{\circ} \mathrm{C}$, banana, em tempos de 0,4 e $8 \mathrm{~h}$, a $50{ }^{\circ} \mathrm{C}$ e pêra em tempos de 0,4 e $8 \mathrm{~h}, 50{ }^{\circ} \mathrm{C}$

\section{Reagentes e soluções}

Foram preparados $500 \mathrm{~mL}$ de cada solução tampão com concentração $0,1 \mathrm{~mol} \mathrm{~L}^{-1}$, utilizando-se água deionizada e os seguintes sais para as respectivas soluções: para preparar o tampão acetato, pHs $4 \mathrm{e}$ 5, utilizaram-se ácido acético (Synth) e acetato de sódio (Grupo Química). Para preparar tampão fosfato, pHs 6 e 7, utilizaram-se fosfato dibásico de sódio anidro (Synth) e fosfato de potássio monobásico (Cinética Química). Para preparação de soluções tampão pHs 8, 9 e 10, foram empregados ácido bórico e borato de sódio (Synth).

Foram preparados $10 \mathrm{~mL}$ de cada solução antioxidante, nas concentrações 0,$01 ; 0,1$ e $1 \mathrm{~mol} \mathrm{~L}^{-1}$, sendo preparadas na solução tampão que resultou na menor oxidação para cada tecido vegetal. Para a banana, maçã e pêra, estudaram-se os anti-oxidantes cisteína (Vetec), 
ácido ascórbico (Carlo Erba), ácido cítrico (Dinâmica), ácido oxálico (Reagen) e bissulfito de sódio (Mallinck) em tampão fosfato ( $\mathrm{pH}=$ 7) e tampão acetato ( $\mathrm{pH}=4 \mathrm{e} \mathrm{pH}=5)$.

\section{Estudo dos fatores que influenciam o processo oxidativo do tecido vegetal}

\section{Efeito do $\mathrm{pH}$}

Com uma faca cortaram-se 8 fatias de cada fruta (banana, maçã e pêra), com espessura de $5 \mathrm{~mm}$ cada, sendo uma fatia para controle e 7 para os testes. As fatias foram colocadas individualmente em placas de Petri e adicionaram-se $34 \mu \mathrm{L} / \mathrm{cm}^{2}$ de soluções tampão acetato $0,1 \mathrm{~mol} \mathrm{~L}^{-1}(\mathrm{pH}=4 \mathrm{e} \mathrm{pH}=5)$, fosfato $0,1 \mathrm{~mol} \mathrm{~L}^{-1}(\mathrm{pH}=6$ e $\mathrm{pH}=7)$ e borato $0,1 \mathrm{~mol} \mathrm{~L}^{-1}(\mathrm{pH}=8, \mathrm{pH}=9$ e $\mathrm{pH}=10)$, cobrindo toda a superfície do tecido vegetal. As placas de Petri foram mantidas fechadas para minimizar a evaporação das soluções. A incubação foi feita por tempos diferentes (dependendo da velocidade de escurecimento de cada fruto), acompanhando-se o processo oxidativo periodicamente, caracterizado pelo escurecimento do tecido devido à formação de melanina. Para registro das imagens foram tiradas fotos digitais em tempos pré-determinados $(0,5$ e $18 \mathrm{~h}$ para banana, 0,3 e 6 h para maçã e 0,4 e 8 h para pêra).

\section{Efeito da luminosidade}

Seis fatias de cada fruta foram acondicionadas em placas de Petri com/sem solução tampão (a que proporcionou menor oxidação de cada tecido) dentro de uma caixa fechada. Foram construídas caixas contendo suporte para adaptação de lâmpadas de UV e fluorescentes para os estudos envolvendo a oxidação dos tecidos vegetais na ausência e presença de luz. As fatias com/sem adição da melhor solução tampão foram mantidas no interior dessa caixa durante intervalos de tempo diferentes, dependendo do tecido estudado, com as lâmpadas acesas. Duas placas, com/sem tampão foram envolvidas em papel alumínio para teste na ausência de luz, duas colocadas sob luz branca e duas sob luz ultra-violeta.

\section{Efeito da temperatura}

Para o estudo de diferentes temperaturas foram cortadas 6 fatias de cada fruta e adicionaram-se $34 \mu \mathrm{L} / \mathrm{cm}^{2}$ da solução tampão mais apropriada. As fatias foram colocadas em placas de Petri tampadas, sendo submetidas a temperaturas de 4,25 e $50{ }^{\circ} \mathrm{C}$. A cada período de tempo (diferente para cada tecido estudado) foram tiradas fotos para visualizar o escurecimento das fatias das frutas.

\section{Estudo na ausência de oxigênio}

Duas fatias de cada fruta foram acondicionadas em vasilha de plástico com uma tampa contendo dois furos (para entrada e saída de nitrogênio). Os estudos foram feitos na presença e ausência de tampão. Imediatamente após o corte, cada fatia foi fotografada e analisada para o cálculo da porcentagem de escurecimento dos tecidos vegetais.

\section{Estudo dos diversos antioxidantes}

Com uma faca, cortaram-se 15 fatias de cada fruta (banana, maçã e pêra), com espessura de $5 \mathrm{~mm}$ cada, sendo uma fatia para controle e 14 para testes. As fatias foram colocadas individualmente em placas de Petri e adicionaram-se $34 \mu \mathrm{L} / \mathrm{cm}^{2}$ de soluções dos seguintes antioxidantes: ácido cítrico $\left(0,01 ; 0,1\right.$ e 1,0 $\left.\mathrm{mol} \mathrm{L}^{-1}\right)$, ácido ascórbico (0,01; 0,1 e $\left.1,0 \mathrm{~mol} \mathrm{~L}^{-1}\right)$, ácido oxálico $\left(0,01\right.$ e $\left.0,1 \mathrm{~mol} \mathrm{~L}^{-1}\right)$, cisteína $\left(0,01 ; 0,1\right.$ e $\left.1,0 \mathrm{~mol} \mathrm{~L}^{-1}\right)$ e bissulfito de sódio $\left(0,01 ; 0,1\right.$ e $\left.1,0 \mathrm{~mol} \mathrm{~L}^{-1}\right)$, cobrindo-se toda a superfície do tecido vegetal. Tamparam-se as placas de Petri com as tampas de vidro respectivas, para minimizar a evaporação de cada solução. A incubação foi feita por tempos dife- rentes (dependendo da velocidade de escurecimento de cada fruta) e acompanhando-se o processo oxidativo periodicamente, observouse o escurecimento do tecido devido à formação de melaninas. Para registro das imagens foram tiradas fotos digitais em tempos pré-determinados (0h00, 5h00 e $18 \mathrm{~h} 00$ para banana, 0h00, 3h00 e 6h00 para maçã e 0h00, 4h00 e 8h00 para pêra).

\section{Cálculo da porcentagem de escurecimento}

Para o cálculo da porcentagem de escurecimento foi utilizado o princípio do Método de Monte Carlo para o cálculo de áreas. Foram utilizados dois métodos para obtenção da porcentagem de escurecimento. Em ambos os métodos, a percepção pessoal do analista definiu quais as áreas escuras e as claras, para então, calcular-se a razão entre elas e obter a porcentagem de escurecimento, através da análise da imagem.

\section{O jogo de grãos}

Em uma caixa, colocou-se uma foto de $15 \times 15 \mathrm{~cm}$ do tecido estudado e aleatoriamente atirou-se um punhado de feijões, contendo 200 grãos. Foram então contados quantos grãos caíram na área escura e no total da figura (considerando-se apenas a fruta e não o fundo). Calculou-se a relação entre eles e repetiu-se 5 vezes o procedimento para se ter uma média dos valores obtidos.

\section{A máscara de pontos}

Utilizando uma planilha eletrônica, foram gerados 200 pares de números aleatórios uniformemente distribuídos, que foram utilizados para construir um gráfico com os pontos distribuídos no plano xy. Este gráfico foi impresso em uma transparência, com tamanho compatível com o das fotos impressas, servindo então como uma máscara de pontos aleatórios que podem ser sobrepostos às fotos dos tecidos vegetais. Para se determinar a porcentagem de área escurecida, adotou-se um procedimento semelhante ao utilizado com os grãos de feijão: foram contados os pontos localizados em regiões consideradas escuras e o total de pontos sobre a fruta, sem se considerar os pontos localizados no fundo da imagem. Por exemplo, na Figura 2 o total de pontos contados na superfície do tecido vegetal foi 130 e na região escura 35 , então, portanto, $27 \%$ da área do tecido foi considerada como escurecida.

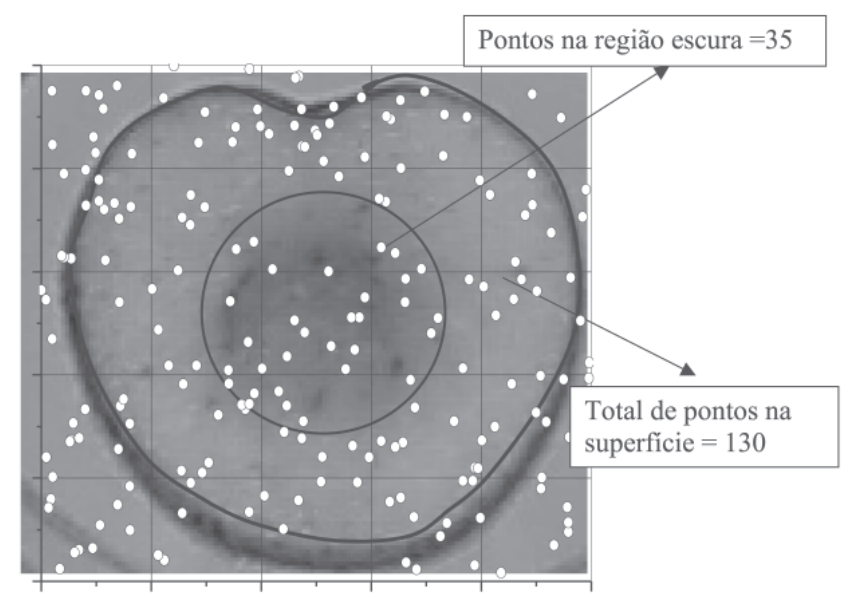

Figura 2. Máscara de 200 pontos gerada utilizando um programa gráfico para realizar o cálculo da porcentagem de escurecimento nos tecidos de frutos estudados 


\section{Análise do escurecimento com programa de edição de imagem}

As análises de padrões de imagem são feitas geralmente com programas de edição de imagens. No caso de análises de escurecimento, utiliza-se uma ferramenta que gera histogramas contendo as distribuições das cores que compõem os "pixels". Duas representações usuais para a cor de um "pixel" são o padrão RGB (vermelho-verde-azul, do inglês "red-green-blue") e a escala de cinza. Em ambos os casos, a intensidade de uma cor é definida por um número inteiro variando de 0 a 255 . Assim por exemplo, a cor verde seria representada por três números, $[0,255,0]$, indicando que para um "pixel" não haveria contribuição alguma das cores vermelha e azul e que a cor verde teria sua intensidade máxima. As cores branca e preta seriam representadas pelos números $[0,0,0]$ e $[255,255,255]$, respectivamente. As imagens obtidas com a câmera digital seguem o padrão de cores RGB, que é útil para se visualizar corretamente as regiões escurecidas, permitindo diferenciá-las de outras partes do tecido vegetal que são naturalmente escuras e não devem entrar no cômputo geral da área escurecida. Por outro lado, como cada cor dá origem a um histograma distinto de distribuição de intensidades, não é possível analisar o escurecimento neste padrão de cores, porque o escurecimento não se dá pelo aumento de uma destas três cores, mas pela variação na proporção entre elas (posto de outra forma, cada fruta oxidada tem uma cor que lhe é peculiar). Portanto, a determinação da área escurecida é feita com a mesma imagem mas utilizando-se a escala de cinza, em que cada "pixel" é representado por um número apenas, também variando entre 0 e 255, este sendo a cor preta e aquele a branca. Ao contrário do método de Monte Carlo descrito acima, a contagem de cores dos "pixels" não é um processo de natureza estatística, sendo de caráter determinista. Neste sentido, trata-se de uma metodologia mais precisa, pois o método de Monte Carlo tem sua precisão afetada pelo número de pontos utilizados no cálculo da área escurecida, enquanto a contagem de "pixels" tem a precisão determinada pela resolução da imagem digital analisada. Por outro lado, este método é menos preciso que o de Monte Carlo por não considerar a cor de regiões mas a de pontos individuais, de modo que entram no cálculo regiões que, a critério do analista, não seriam computadas como escurecidas na análise pelo método de Monte Carlo, por serem consideradas como regiões originalmente escuras (casca, sementes, etc). Este método de análise também não leva em conta o fato de que os diferentes tecidos vegetais têm cores iniciais diferentes, o que não interfere na análise pelo método de Monte Carlo, no qual o critério do analista leva estas variações em conta quando julga quais regiões escureceram. Estas duas deficiências do método de contagem de "pixels" podem ser minimizadas considerando-se a imagem do tecido vegetal no instante de sua preparação como referencial para o escurecimento. Nas análises a serem apresentadas, consideramos o valor de escala de cinza entre 0 e 130 como sendo área escura, tanto para o tecido recém preparado como para as amostras finais, resultando em uma porcentagem de área escura inicial e uma final. A porcentagem de escurecimento é dada então pela diferença entre o valor final e o inicial.

Todas as análises foram feitas utilizando-se o programa GIMP, que pode ser obtido gratuitamente via internet ${ }^{11}$.

\section{Desenvolvimento do material didático}

Com base nas referências bibliográficas sobre química de alimentos $^{3}$, preservação e princípios de enzimologia em alimentos ${ }^{12}$, metodologia de Monte $\mathrm{Carlo}^{7}$, aplicações de diversas metodologias de análise de imagens ${ }^{13-18}$ e diversos artigos de prevenção da oxidação em tecidos vegetais ${ }^{19-25}$, foi desenvolvido um CD-ROM com material didático em formato html contendo uma introdução sobre o tema, toda a metodologia abordada e os resultados obtidos, bem como questões a respeito do estudo desenvolvido.

\section{RESULTADOS E DISCUSSÃO}

\section{Estudos para a prevenção da oxidação}

Foram realizados estudos para obtenção das melhores condições para prevenção da oxidação nos tecidos de maçã Gala, pêra Williams e banana nanica. A seguir estão descritos os resultados para cada estudo realizado, entre eles: presença e ausência de solução tampão nos valores de $\mathrm{pH}$ : 4,0; 5,0; 6,0; 7,0; 8,0; 9,0 e 10, presença/ausência de luz UV-VIS, temperaturas de 4,25 e $50{ }^{\circ} \mathrm{C}$, ausência de oxigênio e presença de antioxidantes: ácido ascórbico, ácido cítrico, ácido oxálico, cisteína e bissulfito de sódio. Para facilitar o cálculo da percentagem de escurecimento, optou-se por utilizar a metodologia da máscara de pontos, sendo os resultados apresentados na Tabela 1. O método de Monte Carlo utilizando o lançamento de feijões foi realizado apenas em parte dos resultados para exemplificar o uso deste tipo de metodologia em aplicações didáticas.

Tabela 1. Estudo e resultado dos parâmetros para prevenção da oxidação enzimática nos tecidos de banana, maçã e pêra

\begin{tabular}{|c|c|c|c|}
\hline Parâmetros/ Fruto & Banana & Maçã & Pêra \\
\hline $\mathrm{pH}(4-10)$ & 7,0 & 4,0 & 5,0 \\
\hline Temperatura $\left(4,25\right.$ e $\left.50{ }^{\circ} \mathrm{C}\right)$ & 4 & 4 & 4 \\
\hline $\begin{array}{l}\text { Luminosidade (UV, VIS e } \\
\text { ausência) }\end{array}$ & ausência & ausência & ausência \\
\hline $\begin{array}{l}\text { Oxigênio (ausência e } \\
\text { presença) }\end{array}$ & ausência & ausência & ausência \\
\hline $\begin{array}{l}\text { Antioxidante (AA, AC, AO, } \\
\text { CIS, BIS)* }\end{array}$ & BIS & BIS & BIS \\
\hline
\end{tabular}

*AA - ácido ascórbico; AC - ácido cítrico; AO - ácido oxálico; CIS cisteína; BIS - bissulfito de sódio.

\section{Efeito do pH}

Como pode ser observado na Figura 3, as melhores soluções tampão para prevenção da oxidação dos tecidos de banana, maçã e pêra foram: tampão fosfato e tampão acetato nos valores de $\mathrm{pH} 7,0$; 4,0 e 5,0, respectivamente. Nesses pHs, o meio biológico de cada fruto é mantido, como se não tivesse sido cortado e, portanto, espera-se que haja menos oxidação. No caso da banana este fato se deve provavelmente à característica não muito ácida do tecido que, com a adição de solução pH 7,0, não apresentou grande modificação nessa característica. A ação da enzima foi mais lenta na presença desse tampão se comparada com as demais soluções, resultando em uma menor oxidação do tecido. Já a maçã, por apresentar-se mais ácida, levou à redução da ação da enzima na presença de tampão acetato ( $\mathrm{pH} 4,0$ ) que como no caso anterior, não mudou bruscamente o $\mathrm{pH}$ do meio. No caso da pêra, sua característica ácida resultou em uma menor oxidação na presença da solução tampão acetato (pH 5,0).

\section{Efeito da temperatura}

Como pode ser observado na Figura 4 , a temperatura de $4{ }^{\circ} \mathrm{C}$ proporcionou menor oxidação, pois a essa temperatura ocorre inibição da atividade enzimática nos tecidos de todos os frutos estudados. Pode-se observar que com o aumento da temperatura há uma aceleração da atividade enzimática, ocorrendo maior escurecimento do fruto. Observou-se também que a presença de tampão ( $\mathrm{pH}=7,0$ 


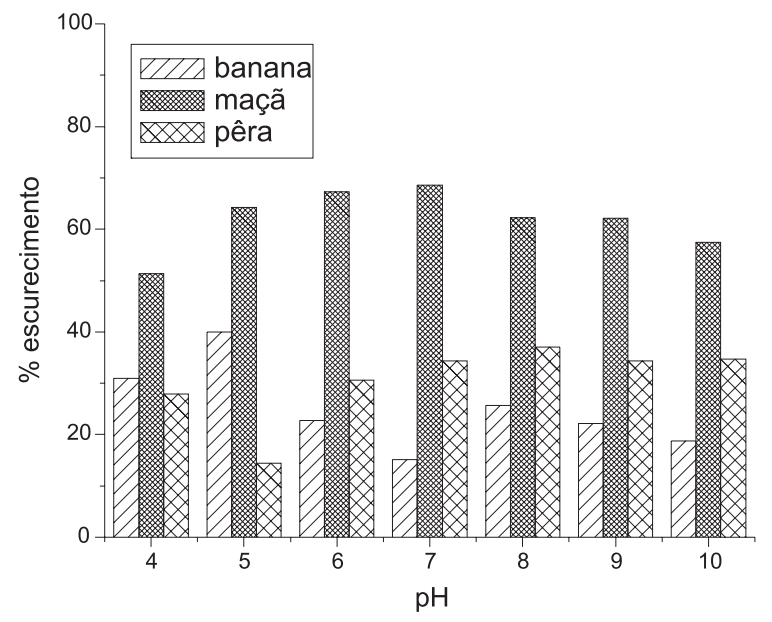

Figura 3. Estudo do efeito do $\mathrm{pH}$ de 4 a 10 na preservação da oxidação nos tecidos de banana, maçã e pêra

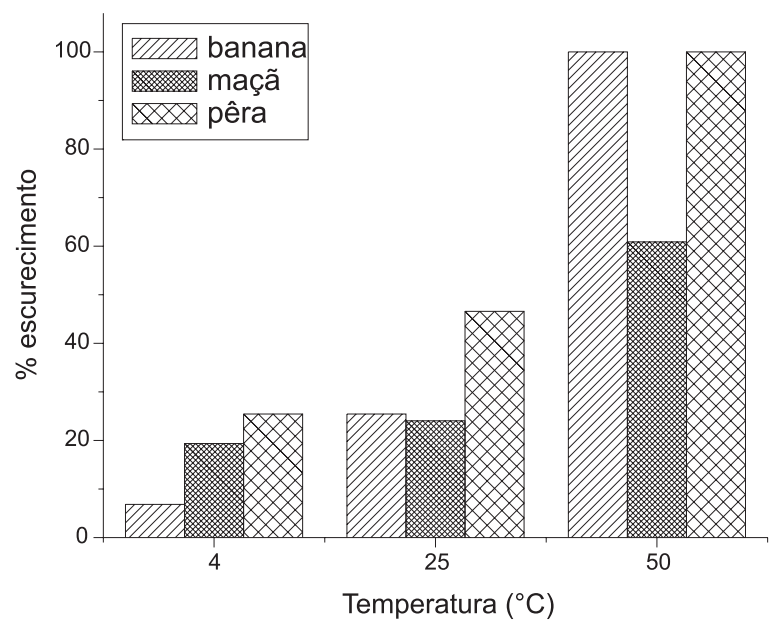

Figura 4. Estudo do efeito da temperatura de 4,25 e $50^{\circ} \mathrm{C}$ na oxidação dos tecidos de banana, maçã e pêra

para banana, $\mathrm{pH}=4,0$ para maçã e $\mathrm{pH}=5,0$ para pêra) sobre os tecidos levou a uma menor porcentagem de escurecimento, devido ao efeito do $\mathrm{pH}$ do tampão e à diminuição do contato do tecido vegetal com o oxigênio atmosférico, proporcionado pelo fino filme de solução tampão sobre o tecido.

\section{Efeito da luminosidade}

Como pode ser observado nas Figura 5, as menores percentagens de escurecimento foram observadas nas fatias com ausência de luz. Isto pode ser explicado pela reação de fotoxidação que, na presença de luz UV-VIS e oxigênio, gera radicais que iniciam o processo de oxidação não-enzimática nos tecidos estudados ${ }^{3}$, o que não ocorre na ausência de luz. No tecido de banana foram observadas as menores porcentagens de oxidação, devido à ação mais lenta da enzima, bem como a maior dificuldade em visualizar a parte oxidada do tecido, uma vez que há o aparecimento de uma coloração amarelada durante o processo.

\section{Estudo na ausência de oxigênio}

Como a polifenol oxidase requer oxigênio para iniciar a reação de escurecimento, procedimentos capazes de eliminar ou de evitar o contato dos vegetais com o oxigênio, como a utilização de embala-

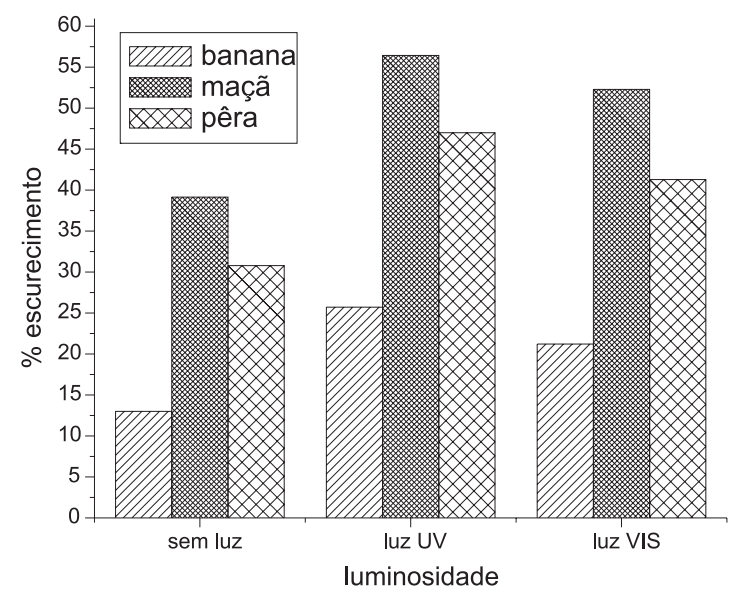

Figura 5. Estudo do efeito de diferentes intensidades luminosas, ou seja, UV, VIS ou ausência de luz, na oxidação dos tecidos de banana, maçã e pêra

gens impermeáveis ou a exclusão do oxigênio em sucos e bebidas com nitrogênio ou $\mathrm{CO}_{2}$, são úteis na prevenção das mesmas.

\section{Estudo com diferentes soluções antioxidantes}

Como pode ser visto na Figura 6, a prevenção do escurecimento de cada fruto depende não só do agente antioxidante, mas também da concentração do mesmo e do tempo de exposição do fruto. Além disso, a espécie de fruto e o grau de maturação do mesmo devem ser considerados, pois quanto mais maduro, maior o grau de oxidação, devido à mudança na composição química do fruto, surgindo um maior número de compostos fenólicos.

Pode-se observar também que a utilização de qualquer agente antioxidante resultou em uma porcentagem de escurecimento menor do que aquela sem a utilização do antioxidante, no caso, apenas na presença de tampão.

O mecanismo de ação na prevenção do escurecimento enzimático pode se dar por: a) inibição direta sobre a enzima, atuando como agente redutor; b) pela redução da quinona formada enzimaticamente ao polifenol de partida ou c) interação direta com intermediários formados durante a ação enzimática, impedindo sua participação em oxidação e condensação adicionais ${ }^{3}$.

O bissulfito de sódio apresentou maior caráter inibitório para todos os frutos estudados, levando a uma menor porcentagem de oxidação, conforme os dados da Figura 6. Um dos compostos mais utilizados pela indústria alimentícia é o bissulfito de sódio (e/ou também o dióxido de enxofre) que como se sabe é um poderoso inibidor das PPO, tanto na forma gasosa como borbulhado em solução.

Os derivados de sulfito contêm propriedades anti-sépticas e ajudam na prevenção da oxidação da vitamina C, mas, por outro lado, sua utilização pode resultar em sabor desagradável, degradação da cor natural do alimento, destruição da vitamina $B_{1}$ e também corrosão de embalagens em latas, além de sua toxicidade se utilizado em altas concentrações ${ }^{3}$.

\section{Comparação entre os métodos utilizados}

Seis estudos foram escolhidos para se comparar as diferentes metodologias de cálculo da porcentagem de área escurecida, que serão designados como segue: $\mathrm{B} 1$ - banana, $\mathrm{pH}=4, \mathrm{t}=18 \mathrm{~h}$; $\mathrm{B} 2$ - banana, temperatura de $50^{\circ} \mathrm{C} \mathrm{t}=4 \mathrm{~h} ; \mathrm{P} 1$ - pêra, temperatura de $4{ }^{\circ} \mathrm{C}, \mathrm{t}=4 \mathrm{~h}$; 

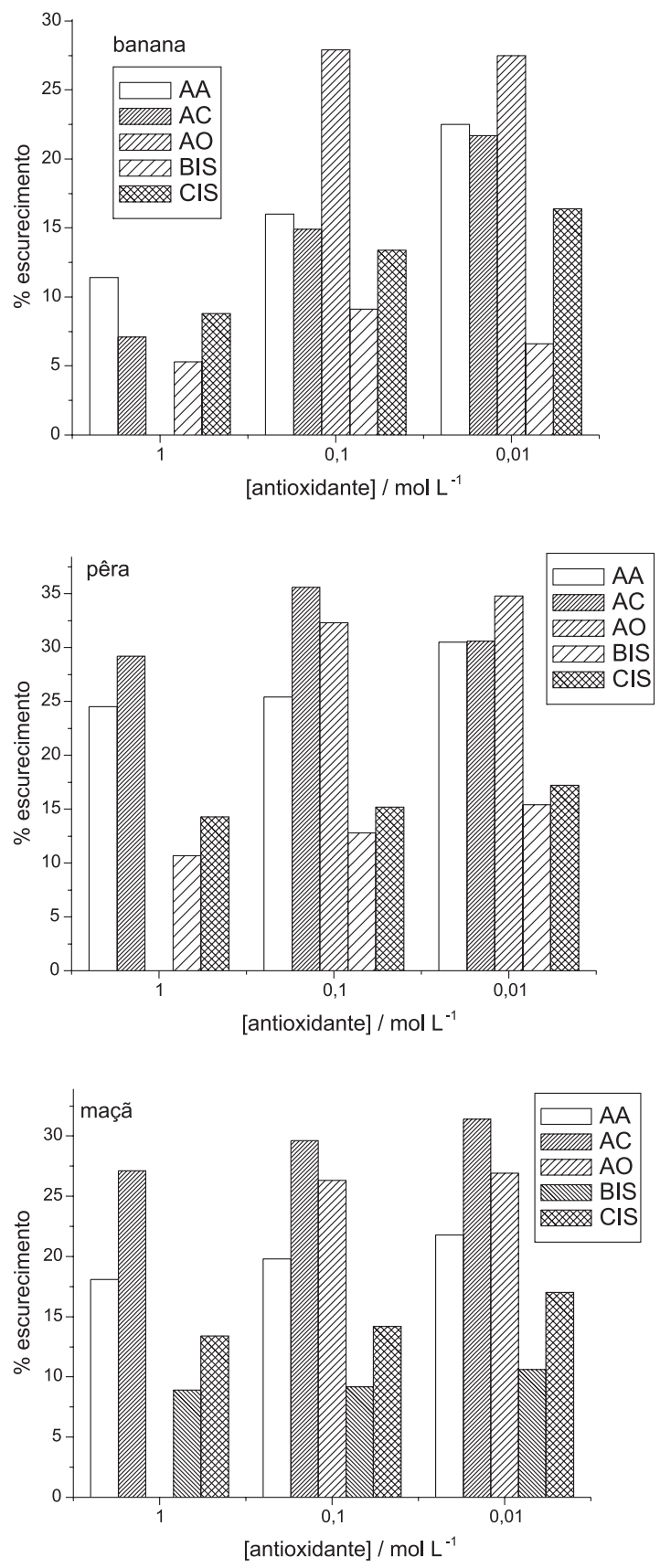

Figura 6. Estudo da ação dos antioxidantes, ácido ascórbico (AA), ácido cítrico (AC), ácido oxálico (AO), cisteína (CIS) e bissulfito de sódio (BIS) na preservação da oxidação dos tecidos de banana, maçã e pêra

$\mathrm{P} 2$ - pêra na ausência de $\mathrm{O}, \mathrm{t}=6 \mathrm{~h}$; M1 - maçã com tampão, $\mathrm{t}=4 \mathrm{~h}$; M2 - maçã sem tampão, $t=4 \mathrm{~h}$. A porcentagem de área escurecida foi calculada através de três métodos: (a) com o uso de um programa de edição gráfica, o GIMP ${ }^{11}$; (b) pelo método de Monte Carlo, utilizando-se números aleatórios gerados por uma planilha eletrônica; e (c) pelo método de Monte Carlo, utilizando-se o lançamento de feijões para se produzir a distribuição de pontos aleatórios. Estes dois últimos devem produzir resultados equivalentes dentro da precisão das medidas, visto que ambos são formas de aplicação da mesma metodologia. Por outro lado, o uso de um programa de edição gráfica de imagens não precisa produzir resultados necessariamente iguais aos obtidos pelo método de Monte Carlo, pois a contagem de "pixels" não é um método estatístico. As duas formas do método de Monte
Carlo foram aplicadas em triplicata em cada tecido estudado e os valores médios encontrados para a área de escurecimento não foram consideradas significativamente diferentes no nível de $95 \%$ de probabilidade, ou seja, as médias calculadas podem ser consideradas estatisticamente iguais com $95 \%$ de confiança, como se esperava. Por outro lado, os valores obtidos pela contagem de "pixels" com o programa GIMP foram diferentes dos obtidos com o método de Monte Carlo, o que também era esperado, mas observou-se a mesma tendência geral nos valores de área escurecida. Trata-se de um método diferente, em que não se definiu a priori as áreas consideradas escuras, como foi feito com o método de Monte Carlo. Portanto, é razoável obter valores diferentes, desde que a tendência geral seja mantida.

Tabela 2. Utilização do método de Monte Carlo usando a máscara de pontos e o método comparativo utilizando o programa de imagem GIMP para o cálculo da porcentagem de escurecimento em alguns estudos nos tecidos de banana, pêra e maçã

\begin{tabular}{lccc}
\hline Estudo* & \multicolumn{2}{c}{$\begin{array}{c}\text { Método de Monte Carlo } \\
\text { Jogo de feijões }\end{array}$} & GIMP \\
& $90 \pm 3$ & $89 \pm 2$ & 69 \\
B1 & $67 \pm 3$ & $67 \pm 5$ & 60 \\
B2 & $16 \pm 2$ & $19 \pm 3$ & 17 \\
P1 & $31 \pm 4$ & $31 \pm 3$ & 40 \\
P2 & $56 \pm 7$ & $54 \pm 5$ & 28 \\
M1 & $54 \pm 3$ & $57 \pm 6$ & 50 \\
M2 &
\end{tabular}

*estudos das frutas banana (B), pêra (P) e maçã (M)

\section{Desenvolvimento do material didático e aplicação do método}

Com base em diversas bibliografias estudadas e na metodologia desenvolvida, foi elaborada uma apresentação didática em formato html com um resumo de todo o material utilizado, que se encontra disponível no site http://lavoisier.dq.ufscar.br/Labs/LABBES. O método será aplicado em um mini-curso futuro, promovido pelo grupo de pesquisa onde foi desenvolvido.

\section{CONCLUSÕES}

O principal objetivo desse trabalho foi proporcionar aos alunos uma nova experiência, que envolvesse conceitos de Química, Bioquímica, Matemática e, principalmente, criatividade e bom senso, uma vez que combinou o conhecimento de processos oxidativos enzimáticos em tecidos vegetais, as técnicas para prevenção do mesmo e o desenvolvimento de um método eficiente para quantificar essa prevenção, que utilizasse só o bom senso do aluno, sem necessitar de equipamentos caros.

O custo de uma câmera digital pode ser justificado pela quantidade de fotos que podem ser obtidas em comparação com o custo de revelação, além de se eliminar a etapa de digitalização de imagens, no caso da utilização dos programas computacionais, o que despenderia tempo e mais dinheiro para compra de scanner.

Deve-se ressaltar ainda que a percepção do analista (aluno) sempre é importante, pois ele definirá qual a região escurecida do fruto após os tratamentos, para qualquer metodologia aplicada. Apesar da existência do programa GIMP que pode ser utilizado para o cálculo da porcentagem de escurecimento, programas específicos que realizam análise de imagem são muito caros e, às vezes, de difícil acesso para o ensino. A metodologia utilizada tende a suprir essa carência, propondo um procedimento simples, além de introduzir os conceitos do método de Monte Carlo. 


\section{AGRADECIMENTOS}

Os autores agradecem à FAPESP pelas bolsas concedidas à L. C. de Carvalho (Proc. 01/12963-OR), a A. F. de Moura (Proc. 01/05891-3) e à K. O. Lupetti (Proc. 00/11512-2).

\section{REFERÊNCIAS}

1. http://www.sbq.org.br/dcurriculares/mec/conteudos.htm, acessada em Outubro 2003.

2. http://www.mec.gov.br, acessada em Outubro 2003.

3. Araújo, J. M. A.; Química de Alimentos: Teoria e Prática, UFV, Imprensa Universitária: Viçosa 1995, p. 8, 65-66, 253.

4. Wang, H. H.; Sun, D. W.; J. Food Engineering 2001, 49, 49.

5. Steinmetz, V.; Roger, J. M.; Moltó, E.; Blasco, J.; J. Agric. Engineering Res. 1999, 73, 207.

6. Yang, Q.; Marchant, J. A.; Computers Electronics in Agriculture 1996, 14, 77.

7. Mackeown, P. K.; Newman, D. U.; Computational Techniques in Physics, Adam Hilger: Bristol, 1987, p. 133-163.

8. Press, W. H.; Teukolsky, S. A.; Vetterling, W. T.; Flannery, B. P.; Numerical Recipes in Fortran 77- The Art of Scientific Computing, $2^{\mathrm{a}}$ ed., Cambridge University Press: New York, 1992.
9. http://www.cut-the-knot.org/ctk/august2001.shtml, acessada em Outubro 2003.

10. http://www.efg2.com/lab/mathematics/buffon.htm, acessada em Outubro 2003.

11. http://www.gimp.org, acessada em Novembro 2003.

12. Copeland, R. A.; Enzymes: A Practical Introduction to Structure, Mechanism, and Data Analysis, $2^{\mathrm{a}}$ ed., John Wiley: New York, 2000.

13. Busch, J. M.; Biochem. Ed. 1999, 27, 171.

14. Friedman, M.; J. Agric. Food Chem. 1996, 44, 631.

15. Son, S. M.; Moon, K. D.; Lee, C. Y.; Food Chem. 2001, 73, 23.

16. Maskan, M.; J. Food Engineering 2001, 48, 169.

17. Artes, F.; Castaner, M.; Gil, M. I.; Food Sci. Technol. Int. 1998, 4, 377.

18. Palou, E.; Lopez-Malo, A.; Barbosa-Canovas, G. V.; Welti-Chanes, J.; Swanson, B. G.; J. Food Sci. 1999, 64,42.

19. Vieira, I. C.; Fatibello-Filho, O.; Talanta 1998, 46, 559.

20. Vieira, I. C.; Fatibello-Filho, O.; Anal. Chim. Acta 1998, 366, 111.

21. Fatibello-Filho, O.; Vieira, I. C.; Anal. Chim. Acta 1997, 354, 51.

22. Fatibello-Filho, O.; Vieira, I. C.; Analyst 1997, 122, 51.

23. Vieira, I. C.; Fatibello-Filho, O.; Anal. Lett. 1997, 30, 895.

24. Ramos, L. A.; Lupetti, K. O.; Cavalheiro, E. T. G.; Fatibello-Filho, O.; Eclet. Quim. 2000, 25, 229.

25. Fatibello-Filho, O.; Vieira, I. C.; Fresenius J. Anal. Chem. 2000, 368, 338.

26. Caruso, C. S.; Vieira, I. C.; Fatibello-Filho, O.; Anal. Lett. 1999, 32, 39. 